\title{
MÉTODO DE BOMBARDEIO AÉREO PARA COMBATE EM INCÊNDIOS FLORESTAIS
}

João Luís Fioravante ${ }^{1}$ Fábio Bonatto ${ }^{2}$

\begin{abstract}
RESUMO
O Brasil, com uma superfície de $8.514 .215,3 \mathrm{~km}^{2}$ (IBGE, 2004), possui pouco mais de $8 \%$ de seu território protegido por unidades de conservação (MMA, 2004). Sua grande diversidade de ecossistemas, aliada às usuais técnicas de manejo da terra e condições climáticas adversas, resulta em uma ampla gama de condições propícias à ocorrência de incêndios florestais de grandes proporções. Comparativamente a outras nações, com menores dimensões e que chegam a dispor de dezenas de aeronaves com capacidade de até 42.000 litros de água ou retardante químico para o combate a incêndios, temos oficialmente apenas uma aeronave de asa fixa especializada no combate a incêndios florestais, além de helicópteros e aviões de reconhecimento sob responsabilidade do IBAMA e de órgãos estaduais de meio ambiente. O COMBFOGO - Esquadrão Aéreo de Combate a Incêndio Florestal (ONG) é uma iniciativa pioneira da sociedade brasileira, visando a minimização dos danos causados pelo fogo ao meio ambiente e com especial enfoque nas Unidades de Conservação. A proposta da organização é a utilização de aeronaves com baixos valores de aquisição e custo operacional, homologadas para o patrulhamento e combate a incêndios florestais, que após pequenas adaptações em seu interior, permitem o lançamento de bombas de água ou retardante químico. Estas aeronaves alcançam uma capacidade total de 300 litros e terão o efeito de retardar o avanço do fogo até a chegada das brigadas terrestres. Palavras-Chave: Incêndios Florestais; Método de Combate Aéreo; Unidades de Conservação.
\end{abstract}

\section{WATER BOMBING METHODOLOGY FOR AERIAL WILDFIRE FIGHTING}

\begin{abstract}
Brazil, which has a territory of $8.514 .215,3$ sq.km, with 692.205 .700 ha of conservation areas, officially relies on a single aircraft dedicated exclusively to wildfire fighting. On the other hand, other nations with smaller dimensions have dozens of such aircraft with load capacities up to 42.000 litters of water or chemical agents, that help both in wildfire fighting and reforesting. COMBFOGO represents an initiative of Brazilian society to minimize that hazard of the wildfires to the environment. This initiative is based in the use of aircraft already present in Brazilian market, with low acquisition and operating costs, authorized for search and combat of such fires. The aircraft should require minor interior modifications to be able to carry and launch water or chemical agent 25 litter bombs. These bombs will slow down the fire advance and give more time to the fire brigades to reach the area.

Key-words: Wildfire Fighting; Aerial Firefighting Method; Wildlife Conservation Areas
\end{abstract}

\section{INTRODUÇÃO}

Os incêndios florestais são considerados como uma das mais graves catástrofes naturais que podem ocorrer em um país, sobretudo aos detentores de megadiversidade de ambientes como o Brasil. Isto se deve, não somente pela elevada freqüência com que ocorrem e extensão que alcançam, mas também devido aos efeitos destrutivos que causam, que além dos prejuízos econômicos e ambientais, podem constituir uma fonte de perigo para as populações e infra-estruturas. Os incêndios florestais são considerados como catástrofes naturais mais pelo fato de se desenvolverem na natureza e por sua possibilidade de ocorrência e características de propagação dependerem fortemente de fatores naturais, do que por serem causados por fenômenos naturais.

\footnotetext{
${ }^{1}$ combfogo@combfogo.org, Matemático, Pres. COMBFOGO, R. Gabrielle Danunzio, 296, Cx. Postal no 18007 - $04626-970$ - São Paulo-SP.

2 fbonatto@cepel.br, Eng. Florestal, MSc., Assessor Técnico COMBFOGO, R. Canavieiras, 753/103, Grajaú - 20561-000 - Rio de Janeiro-RJ.
} 
A intervenção humana pode desempenhar um papel decisivo na sua origem e na limitação do seu desenvolvimento, onde a importância da ação humana sobre estes fenômenos distingue os incêndios florestais das restantes catástrofes naturais (SNBPC, 2004).

No Brasil, a política de prevenção e controle de incêndios florestais foi estabelecida pelo Decreto n. 97635/89 o qual criou o Sistema Nacional de Prevenção e Combate aos Incêndios Florestais - PREVFOGO, atribuindo ao Instituto Brasileiro do Meio Ambiente e dos Recursos Naturais Renováveis - IBAMA, a competência de coordenar as ações necessárias à organização, implementação e operacionalização das atividades relacionadas com a educação, pesquisa, prevenção, controle e combate aos incêndios florestais e queimadas. Em 1990 o PREVFOGO definiu duas linhas de atuação, uma com o objetivo primordial de estabelecer mecanismos emergenciais de proteção contra incêndios nas Unidades de Conservação da União, e outra, de médio prazo, com o objetivo de desenvolver trabalhos que permitissem desenhar a forma de organização e operação do Sistema.

Após dez anos de atuação, uma auditoria realizada em outubro de 2000 pelo Tribunal de Contas da União, apontava falhas no programa de combate a incêndios florestais do IBAMA. Foi identificada uma carência generalizada de recursos humanos e materiais, associada a uma política de liberação de recursos financeiros inadequada que comprometeram a atuação do PREVFOGO, inviabilizando a realização de atividades de prevenção em tempo hábil. As estratégias de combate a incêndios ficaram restritas a ações emergenciais e muitas vezes desencadeadas após o fogo já ter causado danos consideráveis. Com este panorama o TCU decidiu, entre outras ações, que o PREVFOGO deveria implantar um sistema de banco de dados com informações atualizadas sobre a ocorrência de incêndios florestais, firmando acordos com as unidades do Corpo de Bombeiros e o Centro Integrado de Defesa Aérea e Controle do Tráfego Aéreo (CINDACTA) para a criação de um canal de comunicações direto dos focos de incêndio no momento em que eles fossem detectados por aviões civis (TCU, 2000).

Mesmo antes da recomendação do TCU os aviadores brasileiros já haviam estabelecido um procedimento de que, quando em vôo, se avistassem algum incêndio informariam a localização deste utilizando uma freqüência de rádio própria e o controlador de vôo se encarregaria de informar as autoridades. Porém este procedimento não alcançou os resultados pretendidos, pois as ações não eram desencadeadas após o informe ser recebido pelo órgão responsável. O plano caiu em desuso e os pilotos continuaram avistando os incêndios sem ter para quem informar. Desta forma, após muitos anos presenciando estes mesmos fatos e não se conformando com a situação, um grupo de pilotos de linhas aéreas comerciais uniu-se para fundar uma Organização Não Governamental de combate voluntário aos incêndios florestais, o COMBFOGO - Esquadrão Aéreo de Combate a Incêndio Florestal. Os principais objetivos da organização são: executar atividade aérea com finalidades de defesa do meio ambiente; efetuar patrulhamento de áreas de preservação e ou interesse ecológico; detectar e combater focos de incêndio em tais áreas; desenvolver e estimular o desenvolvimento de tecnologia aeronáutica com fins de utilização ecológica; promover a defesa de bens e direitos sociais, coletivos e difusos relativos ao meio ambiente, ao patrimônio cultural; estimular o aperfeiçoamento e o cumprimento da legislação que instrumentalize a consecução dos presentes objetivos.

\section{OBJETIVO}

O objetivo deste trabalho consiste no desenvolvimento de um método de combate a incêndios florestais em Unidades de Conservação por via aérea, simples e de baixo custo, utilizando aeronaves monomotoras, nacionais ou já nacionalizadas, com pequenas modificações em seus interiores para 0 lançamento das cargas de água ou retardante.

\section{REVISÃO BIBLIOGRÁFICA}

De uma forma abrangente, o combate aos incêndios florestais está baseado em um conceito primordial, para que ocorra a combustão há necessidade da combinação de três fatores: combustível, calor e ar (oxigênio), sendo esta combinação descrita como o "triângulo do fogo". Se uma das partes do triângulo for quebrada a combustão não poderá 
ser realizada, tendo-se então que, separando o material combustível de um incêndio através da abertura de aceiros ou estabelecimento de linhas de fogo, quebra-se o triângulo; resfriando o material inflamável abaixo da temperatura de combustão, quebra-se o triângulo; e, removendo-se o ar do processo de combustão, também se quebra o triângulo (SOARES, 1985; WATT, 2002).

O combate a incêndios florestais no Brasil tem sido realizado, predominantemente, por brigadas terrestres que se deslocam através da mata até o local do fogo. Este trajeto pode levar horas e as ferramentas comumente utilizadas são enxadas, abafadores, facões e bombas costais com aproximadamente 20 litros $(20 \mathrm{Kg})$. Devido ao longo tempo gasto para que as brigadas cheguem ao local, o fogo se instala e propaga-se sem controle, o que torna ainda mais difícil a sua extinção, esta luta pode durar horas ou dias, dependendo das dimensões do fogo, das características do material em combustão, das condições climáticas e do número de bombeiros.

A utilização de aeronaves deve ser considerada como uma ferramenta de apoio para o combate a incêndios florestais, não podendo ser considerado como um recurso de controle independente e auto-suficiente. O lançamento aéreo de água ou retardantes químicos sobre a frente de avanço do fogo, quando este apresenta uma grande magnitude $\mathrm{e}$ intensidade não se tem mostrado eficaz. A sua maior eficiência é obtida durante o ataque inicial, procurando conter o incêndio nas duas ou três primeiras horas após o seu início, considerando-se como um bom apoio também para o controle de focos secundários, em tarefas de apoio ao combate indireto, e ainda, apoio quando as equipes de terra se encontram esgotadas ou em áreas remotas. Para uma ação efetiva, deve existir uma permanente coordenação entre o pessoal de terra e o apoio aéreo. A utilização de aeronaves como observadoras aéreas, lançando pára-quedistas ou como aeronaves tanques auxilia muito, mas quem definitivamente controla e extingue $o$ incêndio florestal são as brigadas terrestres.

Uma vigilância eficaz da floresta é essencial como primeiro elo da cadeia de combate a incêndios florestais. Em regiões montanhosas ou de relevo acidentado e de difícil acesso, a detecção imediata de focos de incêndio e o combate de primeira intervenção assumem uma importância crucial. Caso um ou ambos falhem, o terreno, as elevadas temperaturas, $\mathrm{o}$ vento $\mathrm{e}$ a topografia, encarregar-se-ão de transformar um pequeno foco de incêndio inicial em um incêndio de grandes proporções que consome milhares de hectares e que reduz as frentes de combate aos caminhos transitáveis (LPN, 2003).

No Brasil não existem grandes aeronaves-tanque, sendo a participação aérea realizada por helicópteros, que transportam bombeiros e cestas com aproximadamente 300 litros de água ou retardante, ou por aeronaves agrícolas que transportam aproximadamente 2.500 litros, dependendo do modelo utilizado.

Quanto mais cedo for localizado o incêndio e quanto antes for iniciado o seu controle, maiores serão as chances de sucesso, pois o incêndio estará ainda na fase inicial, podendo ser controlado mais rapidamente e com menos recursos, causando menor prejuízo ao meio ambiente.

\section{MATERIAL}

Uma aeronave baseada próximo à Unidade de Conservação pode se deslocar até o local do incêndio rapidamente, levando um agente anti-fogo: água ou retardante. $\mathrm{Na}$ maioria dos casos, chegaria ao local do fogo antes dos bombeiros, fazendo um combate inicial, o qual necessariamente não extingue o fogo, mas o mantém restrito a uma pequena área e com baixa intensidade até a chegada das brigadas terrestres.

Dentro das atuais limitações de recursos, utiliza-se uma aeronave adaptada para o combate a incêndio. Trata-se de um monomotor com uma larga porta lateral, onde a água é transportada em recipientes de polietileno, podendo ser transportados 300 litros divididos em 20 recipientes. Lançados de uma altura de 50 metros sobre o foco do fogo, ao atingir o solo o recipiente estoura liberando a água, extinguindo o fogo por abafamento e resfriamento.

Devido ao fato da água estar envasada até chegar ao solo, não há perdas na atmosfera, o que ocorre quando a água é lançada no ar pelas aeronaves-tanque.

É um método relativamente barato se comparado com a utilização de grandes 
aeronaves, que além de um valor de aquisição muito alto, têm também um elevado custo operacional.

Aeronave: Uma aeronave monomotora terrestre, com capacidade mínima de transporte de carga de $450 \mathrm{~kg}$ (300 litros de água e 2 tripulantes), com autonomia mínima de 4 horas e alcance de $1500 \mathrm{~km}$ e com capacidade para voar sem uma de suas portas.

Bombas: Manufaturadas com material plástico (polietileno), com capacidade para 25 litros cada, nas dimensões de $20 \mathrm{~cm}$ de largura por $120 \mathrm{~cm}$ de comprimento, podendo conter água ou produto químico.

A sonda é uma bomba com capacidade para 5 litros, nas dimensões de $5 \mathrm{~cm}$ de largura e 20 $\mathrm{cm}$ de comprimento, contendo um corante vermelho usado para identificar e corrigir os possíveis erros antes do lançamento das bombas.

Tripulação: Consiste de 2 tripulantes, sendo 1 piloto responsável pela condução da aeronave e 1 lançador responsável pelo manuseio das bombas no interior da aeronave e pelo lançamento das mesmas sobre os focos de incêndio.

Acessórios: O Berço é o dispositivo usado para o lançamento das bombas, tendo a capacidade para até 6 bombas de cada vez, tem $70 \mathrm{~cm}$ de comprimento, $35 \mathrm{~cm}$ de largura e 35 $\mathrm{cm}$ de altura. Está fixado a um pedestal através de um eixo móvel em suas extremidades. O pedestal por sua vez é fixado ao piso da aeronave através dos trilhos do assento dianteiro direito, que é retirado da aeronave para a colocação do berço. Seu funcionamento é muito simples, bastando que o lançador coloque as bombas em seu interior e gire o eixo fazendo com que as bombas caiam por gravidade, através da saída direita da aeronave que teve a porta retirada antes do vôo.

O sistema de miras consiste de duas escalas geométricas, a mira frontal e a mira lateral, situadas no pára-brisa dianteiro da aeronave e na janela dianteira esquerda respectivamente. O piloto utiliza este sistema de miras posicionando a aeronave sobre o foco. Quando julgar estar exatamente sobre o local de lançamento, o piloto observa através da mira lateral algum ponto fora da aeronave, fazendo o mesmo na mira frontal escolhendo algum ponto à frente da aeronave. Estes pontos serão as referências para posicionar a aeronave para os lançamentos, pois ao criar uma linha imaginária do ponto lateral até à aeronave e uma linha imaginária do ponto frontal até à aeronave, o cruzamento destas duas linhas dará a posição exata da aeronave no momento do lançamento. Quanto mais próximos da aeronave estiverem estes pontos mais preciso serão os lançamentos.

\section{MÉTODO}

O método consiste em levar a aeronave sobre o local do foco, voando a uma altura de 50 metros da copa das árvores. Quando sobre o foco o piloto faz as marcações nas miras frontal e lateral, determinando a posição para o lançamento e então ordena ao lançador que lance a sonda. Após o lança-

mento, observa-se o local onde a sonda caiu e faz-se então as correções para o lançamento das bombas.

Estas correções são feitas criando-se um quadrado imaginário sobre o foco, deixando o foco no centro do quadrado. Divide-se o quadrado em 4 quadrantes, numerados no sentido horário em quadrantes 1 , 2,3 e 4 .

\section{Erros prováveis:}

Quadrante 1: a sonda caiu à frente e à esquerda do foco.

Quadrante 2: a sonda caiu à frente e à direita do foco.

Quadrante 3: a sonda caiu atras e à direita do foco.

Quadrante 4: a sonda caiu atras e à esquerda do foco.

\section{Correções possíveis:}

Quadrante 1: posicionar a referência frontal à esquerda na mira frontal e a referência lateral à frente na mira lateral.

Quadrante 2: posicionar a referência frontal à direita na mira frontal e a referência lateral à frente na mira lateral.

Quadrante 3: posicionar a referência frontal à direita na mira frontal e a referência lateral atrás na mira lateral.

Quadrante 4: posicionar a referência frontal à esquerda na mira frontal e a referência lateral atrás na mira lateral.

Outras correções são possíveis intercalando estas quatro correções básicas. 
A trajetória da aeronave para o lançamento descreve um retângulo, onde o foco é posicionado exatamente abaixo e no meio de um dos lados maiores. Este segmento é chamado de perna do vento, pois a aeronave voa no sentido favorável à direção do vento, este segmento tem $2 \mathrm{~km}$ o que equivale a aproximadamente 3 minutos de vôo. É realizado à 50 metros da copa das árvores aproximadamente com velocidade constante.

No término da perna do vento a aeronave efetua uma curva à esquerda e ingressa na perna de través, segmento que tem aproximadamente 30 segundos de vôo. Neste segmento a aeronave sobe para 150 metros de altura.

Após completar a perna de través a aeronave efetua curva à esquerda e ingressa no lado maior oposto à perna do vento, este é chamado de perna contra o vento, pois a aeronave voa no sentido contrário à direção do vento, tem $2 \mathrm{~km}$ de comprimento ou 3 minutos de vôo. É nesta posição que se realizam as observações dos resultados dos lançamentos. $\mathrm{Na}$ perna contra o vento a aeronave deve manter 150 metros de altura do solo.

No fim da perna contra o vento a aeronave realiza curva à esquerda e estará entrando na perna base, onde deve reiniciar a decida para 50 metros de altura, ao término de 30 segundos estará novamente curvando à esquerda e novamente ingressará na perna do vento para realizar outro lançamento sobre o foco.

\section{CONCLUSÃO}

Os incêndios florestais queimam grandes áreas no território nacional, em 2003 foram mais de 63.000 focos, consumindo remanescentes de mata ciliar, áreas protegidas ao redor das nascentes, destruindo as mais diversas formações florestais e atingindo várias espécies da fauna e seus habitats. Sua fumaça obstrui a visibilidade nas estradas e aeroportos, suas chamas interrompem linhas de transmissão elétrica e deixam resíduos na atmosfera.

O Brasil tem sido citado e criticado por organismos internacionais, por não dar a este problema uma solução mais eficaz.

O Esquadrão Aéreo de Combate a Incêndios Florestais - COMBFOGO tem pouco mais de um ano de existência e este primeiro ano foi totalmente dedicado para a estruturação interna, com a aquisição de materiais, aquisição de know-how e treinamento dos integrantes. Hoje nossos pilotos já estão em fase final de treinamento para cumprir as tarefas planejadas.

Nosso corpo técnico e grupo de colaboradores incluem, além de aeronautas e pesquisadores, ambientalistas, artistas plásticos, políticos e estudantes, totalizando hoje mais de 25 pessoas.

A proposta desta ONG é plenamente viável, devendo ser apoiada por outras ONGs e orgãos públicos, pois apresenta uma solução brasileira, simples e relativamente barata, se comparada com as soluções usadas no exterior. Esta iniciativa poderá ser futuramente ampliada para uma escala nacional, cobrindo todas as unidades de conservação, federais, estaduais e municipais.

A tecnologia utilizada está sendo gerada no Brasil e o uso de tecnologia aeronáutica para o combate à incêndios florestais causa impacto na sociedade por ser um ícone de modernidade, eficiência e confiança.

\section{REFERÊNCIAS}

BATISTA, A. C.; SOARES, R. V. Manual de prevenção e Combate a Incêndios Florestais. 1997.

BRUCK, E. C. Unidades de Conservação no Brasil Cadastramento e Vegetação 19911994. 1995.

CARNEIRO. A. C. A História do Ambientalismo. 2003.

CONAMA - Conselho Nacional do Meio Ambiente. Resoluções CONAMA Anotada. 2002

IBGE. Brasil em Síntese. Instituto Brasileiro de Geografia e Estatística - Diretoria de Geociências. Disponível em: <http://www. ibge.gov.br/brasil_em_sintese $>$. Acesso em 06 de abril de 2004.

LPM - Liga para a Proteção da Natureza. Contributo da LPN para a Elaboração do Livro Branco sobre Incêndios Florestais Incêndios Florestais ' $\mathbf{2 0 0 3 ,}$ a reflexão inadiável. Lisboa, 2003. 
MMA. Áreas Protegidas do Brasil. Ministério do Meio Ambiente - Diretoria do Programa Nacional de Áreas Protegidas-DAP. Brasília, DF. Disponível em: <http://www. mma.gov.br/port/sbf/dap/apconser. $\mathrm{html}>$. Acesso em 06 de abril de 2004.

NEPSTAD, D.C.; MOREIRA, A. G.; ALENCAR, A. A. Flames in Rain Forest: Origins, Impacts and Alternatives to Amazonian Fires. 1999.

SNBPC - Serviço Nacional de Bombeiros e Protecção Civil. Prevenção e Proteç̧ão Incêndios Florestais. Disponível em: $<$ http://www2.snbpc.pt $>$. Acesso em 08 março 2004.
SOARES, R.V. Incêndios Florestais Controle e Uso do Fogo. FUPEF, Curitiba. 213 p. 1985.

TCU - Tribunal de Contas da União. Auditoria no IBAMA aponta falhas em programa de combate a incêndios florestais. Informativo TCU. Disponível em: $<$ http://www.tcu.gov.br /imprensa /informativotcu/2000/outubro>. Acesso em 19 de março de 2004.

VEIGA, J. E. Ciência Ambiental. 1998.

WATT, J. Letter to the Blue Ribbon Panel on Aerial Firefighting. Sacramento, CA, 2002. Disponível em: <http://www.wildland fire.com/docs/jwattbrp.htm>. Acesso em 06 de abril de 2004. 